\title{
EDCF가 바라본 2017년 동료검토 \\ 주요 내용 및 향후 과제
}

목 차

I. 들어가며

II. 2017년 동료검토 주요 내용

1. 2012년 동료검토 이행 성과

2. EDCF 방문 결과

3. 수원국 캄보디아 방문 결과

4. 혁신주제 발표: PPP를 통한 민간 부문과의 파트너십 확대

III. 향후 과제

1. 전략적 성과 관리 및 평가

2. 원조의 질과 효과성 제고

3. 시스템 개선 및 소통 강화

4. 시민사회와의 협력 강화

IV. 시사점 및 결론

참고 문헌 


\section{요 약}

한국은 경제협력개발기구(Organisation for Economic Cooperation and Development, $\mathrm{OECD}$ ) 개발원조위원회(Development Assistance Committee, DAC) 가입 이후 지난해에 두 번째 동료검토(Peer Review)를 받았다. 2017년 동료검토는 한국 정부와 여러 원조 시행기관들을 대상으로 광범위하게 실시되었으나, 본 원고는 대외경제협력기 금(Economic Development Cooperation Fund, EDCF) 입장에서 바라본 동료검토 의 주요 내용과 개선 과제를 정리해 본다.

$\mathrm{EDCF}$ 는 2012년 동료검토 이후 세이프가드 수립, 취약국 지원 가이드라인 수립, 성 인지적 관점 적용 기준의 제정, 국별 프로그래밍 체제 도입 및 시행 등의 성과를 거두었 다. 또한 개발재원이 극히 부족한 최빈국 지원을 위한 양허성 차관의 역할을 인정받았다. 캄보디아 현지에서도 수원국 개발 계획에 부합하는 고양허성 차관 제공, 프로그램 미션 을 통한 중기 예측성 제고 등이 높게 평가되었다. 한편, $\mathrm{EDCF}$ 는 $\mathrm{DAC}$ 동료검토 회의에 서 혁신주제로 민관 협력(Public-Private Partnership, PPP) 사업 지원 모델과 사례를 발표하여 동료 회원국들로부터 많은 관심과 지지를 받았다.

2017년 동료검토 권고 사항 12 개 중 $\mathrm{EDCF}$ 에 해당되는 것은 9개 정도이며 $\mathrm{EDCF}$ 는 전략적 성과 관리 및 평가, 원조의 질과 효과성 제고, 시스템 개선 및 소통 강화, 시민사회 와의 협력 강화 등을 위해 각 권고 사항별로 개선 노력을 기울여야 할 것이다.

$\mathrm{EDCF}$ 는 한국 정부의 $\mathrm{ODA} / \mathrm{GNI}$ 목표 달성과 같은 양적 확대를 위해서는 개발도상 국의 대규모 랜드마크 사업을 발굴하여 차관 승인 규모를 대폭 확대하고, 민간 재원을 포함한 개발 재원 동원에 필요한 촉매제 역할을 충실히 수행해야 할 것이다. 한편, 비구속 성 차관 지원 확대라는 권고 사항을 이행하기 위해서는 $\mathrm{EDCF}$ 관계자들의 다양한 노력 이 필요하다. $\mathrm{EDCF}$ 는 협조융자, 프로그램 차관 등 비구속성 지원 수단을 최대한 활용해 야 하고, 한국 기업은 국제 경쟁입찰에서 수주 경쟁력을 확보해야 하며, 한국 정부는 원조의 비구속성화에 대한 국민적 인식을 개선시키려는 노력을 경주해야 할 것이다. 


\section{I. 들어가며}

한국은 2010년 경제협력개발기구(Organisation for Economic Cooperation and Development, 이하 OECD) 개발원조위원회(Development Assistance Committee, 이하 $\mathrm{DAC}$ )에 가입한 이후 2012년에 이어 지난해 두 번째 동료검토(Peer Review)를 받았다. 2017 년 동료검토는 2012년 동료검토 이후 한국의 개발협력 개선 노력을 종합적으로 평가하고, 앞으 로 한국의 공적개발원조(Official Development Assistance, 이하 ODA)가 더 발전하기 위해 필요한 과제들을 동료 회원국들과 살펴볼 수 있는 좋은 기회였다.

우선, 한국은 수원국에서 주요 원조 공여국으로 발돋움하여 원조가 개발도상국의 경제성장과 인적자원 개발을 이끌어 낼 수 있다는 모범사례를 보여 주었고, 개발 과정에서 축적된 지식과 전문성을 바탕으로 현재 국제 원조사회에서 주요 역할을 수행하고 있다는 평가를 받았다.

물론 위와 같은 긍정적인 평가만 있었던 것은 아니다. 개발협력 비전과 정책, 개발 재원의 조달과 배분, 개발협력 의사 결정 구조와 체계, 원조 지원 수단과 파트너십, 성과 관리 및 평가, 인도적 지원 노력 등에 있어서 앞으로 개선이나 보완이 필요한 부분이 있다는 권고도 받았기 때문이다.

2017년 동료검토는 한국 정부와 여러 원조 시행기관을 대상으로 광범위하게 실시되었고 또 성과 평가와 권고 사항은 한국의 모든 $\mathrm{ODA}$ 에 해당하는 것이나, 대외경제협력기금(Economic Development Cooperation Fund, 이하 $\mathrm{EDCF}$ ) 설립 30주년을 맞는 해에 실시되었기에 $\mathrm{EDCF}$ 입장에서는 남다른 의미로 다가왔다. 따라서 본 원고는 한국의 유상 원조를 맡고 있는 $\mathrm{EDCF}$ 입장에서 바라본 2017년 동료검토의 주요 내용과 개선 과제를 정리해 본다. 


\section{2017년 동료검토 주요 내용}

\section{2012년 동료검토 이행 성과}

2012년 동료검토 권고 사항 중 $\mathrm{EDCF}$ 해당 사항으로는 성평등.여성 권한 강화·환경 및 기후변화 등의 이슈 주류화, 취약국 등의 경제 상황과 재정 지배구조에 대한 고려, 원조 효과성 제고를 위한 중기 원조 계획 예측 가능성 확보 등을 들 수 있다. $\mathrm{EDCF}$ 는 이러한 권고 사항을 충실히 이행하기 위하여 그동안 제도 및 업무 프로세스를 계속 개선해 왔다. 그중 주목할 만한 개선 사항은 $\mathrm{EDCF}$ 세이프가드 수립, $\mathrm{EDCF}$ 취약국 지원 가이드라인 수립, 성 인지적 관점 적용 기준 제정, 국별 프로그래밍 체제 도입 및 시행 등이다.

먼저, $\mathrm{EDCF}$ 는 4년이 넘는 개발 과정을 거쳐 2016년 2월에 세이프가드를 도입하였다. 세이 프가드는 기본적으로 사업 개발에 따른 환경 사회 영향 및 리스크를 사전에 파악하여 차주가 적절한 저감 대책을 수립토록 요구하는 것이다. $\mathrm{EDCF}$ 는 차관 신청서 접수 시부터 대상 사업의 위험 등급을 분류하고, 그 등급에 따라 차주가 환경사회영향평가보고서(Environmental and Social Impact Assessment, ESIA) 또는 기초환경사회조사서(Initial Environmental and Social Examination, IESE)를 제출토록 요구한다. $\mathrm{EDCF}$ 는 동 보고서를 바탕으로 환경사회 영향심사를 실시하고, 차주가 적절한 환경사회위험 저감 대책을 수립케 한 후 저감 대책의 이행 상황을 점검하고 있다.

또한 $\mathrm{EDCF}$ 는 양성평등 증진과 성 주류화(gender mainstreaming)라는 국제개발협력 동 향을 반영하여 '성 인지적 관점 적용 기준'을 2016년 5월에 제정하여 시행하고 있다. $\mathrm{EDCF}$ 는 단기적으로 성 주류화가 용이한 분야(교육, 보건, 수자원 등)에 성 인지적 관점을 우선 적용하고 있고 또 사업 준비, 심사, 모니터링, 평가 등 각 사업 단계마다 양성평등을 증진할 수 있는 요소들을 반영하여 성 주류화를 추진하고 있다.

다음으로, $\mathrm{EDCF}$ 는 취약국에 대한 원조 제공 시 수원국의 경제 상황과 재정 거버넌스를 면밀히 검토하라는 동료검토 권고에 따라 ' $\mathrm{EDCF}$ 취약국 지원 가이드라인'을 2017년 5월에 수립하였다. 동 가이드라인은 $\mathrm{EDCF}$ 자체 취약국 선정 기준과 취약국 지원 원칙 및 세부 이행 방안을 상세히 제시하여 수원국의 취약성에 따른 사업 지연, 불필요한 분쟁, 사업 효과 저해 등을 예방하고 있다.

아울러, $\mathrm{EDCF}$ 는 중기 원조 계획의 예측 가능성을 제고하라는 2012년 동료검토 권고 사항을 
이행하기 위해 2015년부터 국별 프로그래밍 체제를 도입하여 2016년부터 본격 시행하고 있다. 이에 따라 $\mathrm{EDCF}$ 는 주로 중점 지원국을 대상으로 중기 후보 사업을 체계적으로 발굴하기 위해 정부 대 정부(Government to Government, G2G) 차원의 프로그램 미션을 직접 실시하고 있다. 프로그램 미션 시 수원국의 국가개발계획 및 개발 수요를 비롯해 한국 기업의 경쟁력, 진출 수요 등을 종합적으로 고려하여 부가가치가 크고 또 원조 효과가 높은 사업을 중심으로 수원국과 $\mathrm{EDCF}$ 간 협의를 통해 중기(3년) 후보 사업의 포트폴리오를 수립함으로써 차관 사업 의 예측 가능성을 높이고 있다.

\section{EDCF 방문 결과}

OECD DAC 사무국과 2개 회원국 대표(뉴질랜드, 미국)로 구성된 검토단은 2017년 6월에 한국을 방문하고, 1 주일(6.19. 23.)에 걸쳐 관련 정부 부처·기관 및 시민사회 단체 등과 다양 한 주제에 대한 심층 면담을 진행하였다. 검토단은 $\mathrm{EDCF}$ 를 방문하여 대략 12 개 사항을 질의하 였고, 그중 빈곤층 친화적인 성장 지원 방법, 최빈국 지원 비중의 확대 필요성 및 리스크 관리 방법 등을 상세히 논의하였다.

먼저, 검토단은 지원 사업 선정 시 빈곤층 친화적인 성장(pro-poor growth)을 고려하는 방법을 질의하였고, $\mathrm{EDCF}$ 는 수원국의 개발 수요를 최대한 반영하는 재정 사업을 선정하여 고양허성 차관으로 지원하고 있다고 답하였다. 수원국 재정 사업은 기본적으로 상업성이 없어 정부가 부담하는 공공투자 사업이면서 주로 개발 소외 지역에서 시행되는 경우가 많기 때문에 빈곤층에 해택이 돌아간다고 설명하였다.

또한 검토단은 $\mathrm{DAC}$ 의 최빈국 지원 확대 공약1)을 언급하며, $\mathrm{EDCF}$ 가 최빈국이 아닌 중소득 국을 중심으로 차관을 지원하고 있지 않은지 문의하였다. 이에 $\mathrm{EDCF}$ 는 최근 5년간 최빈국 (Least Developed Countries, $\mathrm{LDCs}$ ) 지원 비중이 연간 집행액의 $44 \%$ 수준이라고 설명하였 고, 검토단은 이를 높게 평가하면서 빈곤국에 대한 고양허성 차관 지원이 계속 확대되어야 한다고 역설하였다. 즉, 검토단은 개발 재원 수요에 비해 지원이 턱없이 부족한 개발도상국, 특히 최빈국을 지원하기 위해 $\mathrm{EDCF}$ 가 제공하는 양허성 차관의 역할을 인정한 것이다.

한편, 검토단이 질의한 최빈국 지원 리스크와 관련하여 $\mathrm{EDCF}$ 는 기본적으로 최빈국이 감당 할 수 있는 수준을 고려하여 차관을 제공한다고 답하였다. 구체적으로 $\mathrm{EDCF}$ 는 국제통화기금

1) 2014 년 12 월, $\mathrm{DAC}$ 회원국은 최빈국에 대한 $\mathrm{ODA}$ 지원 감소 현황을 반전시키고, ODA 차관의 통계보고 방식을 현대화하는 역사적 합의를 도출하였음. 최빈국에 대한 고양허성 차관 지원을 유인하는 체계를 고안함으로써 긍정적 변화가 기대됨(OECD, 2016). 
(International Monetary Fund, IMF) 및 세계은행(World Bank)이 개발도상국의 채무상환 능력을 분석한 결과를 토대로 상환 능력과 채무관리 능력이 충분한 국가에만 차관을 지원하고, 고양허성 차관 지원을 통해 수원국의 상환 부담을 최소화하기 때문에 최빈국 지원 리스크는 크지 않다고 설명하였다.

\section{3. 수원국 캄보디아 방문 결과}

검토단은 한국 방문에 이어 캄보디아 프놈펜을 방문(6.26. 30.)하였고, 한국대사관, $\mathrm{EDCF}$ 및 한국국제협력단(Korea International Cooperation Agency, 이하 KOICA) 프놈펜 사무 소, 캄보디아 정부 부처(개발위원회, 경제재무부, 교육부, 농촌개발부, 보건부), 대한무역투자진 흥공사(Korea Trade-Investment Promotion Agency, 이하 KOTRA) 사무소 등을 방문해 $\mathrm{ODA}$ 관계자들과 면담하였다. 검토단은 캄보디아 정부 부처와 면담 시 수원국의 솔직한 의견을 듣기 위하여 한국 측 관계자는 배석하지 않도록 하였다.

검토단은 한국에서 확인한 사항과 캄보디아 사업 현장에서 이루어지는 활동을 비교하였다. 이를 통해 검토단은 캄보디아의 우선순위와 수요를 반영한 한국의 개발원조 활동이 현지에서 높은 평가를 받고 있다는 점을 직접 확인하였으며, 캄보디아 정부의 개발 계획을 뒷받침하는 고양허성 차관 제공, 프로그램 미션을 통한 중기 예측성 제고, $\mathrm{EDCF}-\mathrm{KOICA}$ 현지 사무소의 'One roof' 협력 체제, 대사관을 통한 조정 기능의 강화 등을 주요 성과로 파악하였다. 반면, 현장 인력 확충, 무상 원조 창구 단일화, 사무소 권한 강화, 시민사회의 잠재력 활용 등은 다소 보완해야 할 부분으로 제시하였다.

이외에도 검토단은 한국이 제조업·관광·농업 부문에 대한 민간투자, 우호적인 이주 정책, 이주자 송금 증가 등 개발원조 이외의 분야에서 다양한 협력 관계를 통해 캄보디아의 경제성장 과 자본 유입을 촉진하고 있다고 평가했다. 또한 검토단은 $\mathrm{ODA}$ 의 촉매적 역할을 강조하며 공적수출금융, 민간투자 등 광범위한 개발재원 분석을 위한 정보 수집에도 관심을 기울였다.

\section{4. 혁신 주제 발표: PPP를 통한 민간 부문과의 파트너십 확대}

한국에 대한 $\mathrm{DAC}$ 동료검토회의는 12 월 6 일 파리 $\mathrm{OECD}$ 회의장에서 개최되었으며, 20 여 개 $\mathrm{DAC}$ 회원국과 아랍에미리트, 멕시코 등이 참석하였다. 회의는 혁신주제 토의와 일반 주제 토의2)로 구분되어 진행되었으나. 본 원고에서는 $\mathrm{EDCF}$ 와 관련된 혁신주제 토의 내용만을 다루

2) 일반 주제로는 한국의 개발협력 특징을 반영한 두 가지 토의 주제인 '글로벌 시민의식 교육'과 '범정부 개발협력 
고자 한다.

혁신주제 토의는 2017년 DAC 동료검토 회의에 새롭게 도입된 사항인데, 피검토국에서 동료 회원국과 공유 또는 토의하고자 하는 주제를 직접 선정하여 발표하게 된다. $\mathrm{EDCF}$ 는 한국 정부의 민간 파트너십 정책에 맞추어 민간 부문의 자금과 전문성을 개발협력에 활용하려는 노력을 구체적인 지원 사례를 들어 설명하였다.

$\mathrm{EDCF}$ 는 민간 부문과의 파트너십을 확대하기 위해 그동안 민관 협력(Public-Private Partnership, 이하 PPP) 방식의 사업을 지원하는 데 주력해 왔다고 발표했다. 특히, 아래<표 $1>$ 의 세 가지 PPP 지원 모델에 따라 사업 발굴과 금융 지원을 해왔다고 설명하였다. 각 지원 모델별로 금융 지원 사례를 하나씩 구체적으로 소개함으로써 지속가능개발목표(Sustainable Development Goals, SDGs) 맥락에서 ODA의 민간투자 촉진 역할을 집중 조명하였다.

〈표 1〉 EDCF의 PPP 지원 모델

\begin{tabular}{c|l}
\hline \multicolumn{1}{c|}{ 지원 방식 } & \multicolumn{1}{c}{ 지원 내용 } \\
\hline 부대 인프라 지원 & $\begin{array}{l}\text { 민간투자 유치 환경 조성과 PPP 사업의 사업성 제고 등을 위하여 PPP 사업의 } \\
\text { 부대 인프라를 구축하는 수원국 재정 사업에 대한 금융 지원 }\end{array}$ \\
\hline 사업 부문 분할 지원 & $\begin{array}{l}\text { 사업성이 있는 PPP 사업 설계를 위하여 PPP 사업 부문과 연계하여 수원국 정부가 } \\
\text { 부담해야 하는 재정 사업 부문에 대한 금융 지원 }\end{array}$ \\
\hline SPC 앞 투자 지원 & $\begin{array}{l}\text { 프로젝트 파이낸싱(PF) 방식의 사업 시행을 위한 특수목적회사(Special Purpose } \\
\text { Company, SPC) 설립을 위하여 수원국 정부가 분담해야 하는 출자금 또는 대여금 } \\
\text { 에 대한 금융 지원 }\end{array}$ \\
\hline
\end{tabular}

출처: 저자 작성

또한 $\mathrm{EDCF}$ 는 그간 $\mathrm{PPP}$ 사업의 지원 경험을 바탕으로 개발재원의 민간투자 유인 효과를 수원국 소득 그룹별로 제시하였다. 예컨대, 중소득국의 경우에는 개발재원이 대규모 민간투자를 동원할 수 있는 잠재력을 갖춘 반면, 최빈국이나 취약국에서는 재원 동원보다는 민간의 전문성을 개발 효과 창출로 연결시키는 촉매제 역할이 더 클 수 있다고 설명하였다.

이와 같은 $\mathrm{EDCF}$ 의 $\mathrm{PPP}$ 를 통한 민간 부문과의 협업 사례는 미국, 일본, $\mathrm{EU}$, 아일랜드, 호주, 뉴질랜드 등 주요 회원국들의 높은 관심과 지지를 받았다. 또한 $\mathrm{EDCF}$ 의 $\mathrm{PPP}$ 지원 사업 사례에 대해 다수의 질문이 이어지면서 $\mathrm{OECD}$ 개발재원 논의가 실제 원조 시행 기관의 사업에서 어떻게 구현되는지에 대한 회원국들의 많은 관심을 확인할 수 있었다.

조정 및 정책 정합성’을 선정함. 


\section{III. 향후 과제}

2017년 동료검토 결과, 한국에 제시된 권고 사항은 모두 12 개 항목이다. 이중 $\mathrm{EDCF}$ 에 직간 접적으로 해당하는 것은 대략 9 개 항목인 것으로 파악된다. $\mathrm{OECD}$ 의 최종 보고서3)를 보면 권고 사항은 전략적 성과 관리 및 평가, 원조의 질과 효과성 제고, 시스템 개선 및 소통 강화, 시민사회와의 협력 강화라는 4 개의 소제목으로 대략 구분해 볼 수 있다. 따라서 상기 소제목에 따른 각 권고 사항별로 $\mathrm{EDCF}$ 의 현황 및 개선 방향을 살펴보기로 한다.

\section{1. 전략적 성과 관리 및 평가}

\section{가. (권고 사항 2) 시행 기관의 성과 관리 및 평가 강화}

$\mathrm{EDCF}$ 는 평가 결과의 활용도 제고, 평가 품질 향상, 내부 평가역량 강화를 평가의 기본 방향으로 설정하고 완공평가 후 2 년 경과 사업 중에서 적합한 사업을 평가 대상 사업으로 선정하여 사후평가를 실시하고 있다. 또한 국제 수준에 맞는 정보 공개 기준을 이미 수립 (2014.11.)하여 평가보고서를 대중에 공개하고 있다.

$\mathrm{EDCF}$ 는 한국 정부의 정보 공개 노력에 더욱 적극적으로 동참하기 위하여 앞으로 수원국 및 한국 내 공동 워크솝 개최, 대내외 이해관계자 교육, 다양한 학술 활동 전개 등을 통해 평가 과정 및 결과에서 얻은 지식과 교훈을 공유하는 한편, 한국이 2015년에 가입한 국제원조투 명성기구(International Aid Transparency Initiative, 이하 IATI)에 대한 정보 공개 항목도 더욱 확대하여 원조 정보의 투명성을 보다 높여야 할 것이다.

\section{2. 원조의 질과 효과성 제고}

\section{가. (권고 사항 3) ODA/GNI 목표 달성 계획 수립 및 비구속화 - 최빈국 지원 강화}

$\mathrm{EDCF}$ 는 정부의 $\mathrm{ODA}$ 규모 확대 정책에 따라 매년 $\mathrm{EDCF}$ 차관 승인 및 집행 규모를 지속적 으로 확대하고 있다. 또한 정부의 ODA 기본 계획에 따라 비구속성 차관 비중도 계속 증대해 2016년에는 연간 승인액의 $52 \%$ 에 달하였고, 최빈국에 대한 차관 지원 비중도 최근 5년간

3) OECD. 2017. "Review of the Development Co-operation Policies and Progrmames of Korea." DCD/DAC/ AR(2017)2/26/PART1/FINAL. Paris: Organisation for Economic Cooperation and Development (OECD). 
평균적으로 연간 집행액의 $40 \%$ 이상을 차지하고 있다.

$\mathrm{EDCF}$ 는 정부의 2020년 비구속성 차관 비중 목표(연간 전체 차관 승인액의 $55 \%$ 이상을 비구속성으로 제공)를 달성하기 위해 다자개발은행(Multilateral Development Bank, 이하 $\mathrm{MDB})$ 협조 융자, $\mathrm{PPP}$ 사업, 프로그램차관 등 비구속성 지원 수단을 적극 활용하여 차관의 비구속성 비중을 지속적으로 늘려 나가야 한다. 또한 중기 재원 배분 계획 등을 수립·운영하여 최빈국 및 취약국에 대한 지원 비중을 일정 비율 이상으로 계속 유지하려는 노력도 필요하다.

\section{나. (권고 사항 4) 현지 정책 대화 심화}

EDCF는 범정부 국가협력전략(Country Partnership Strategy, CPS)과 연계되는 수원국 별 중기 지원 계획을 수립하기 위해 정부 간 정책협의회를 개최하고 있다. 또한 베트남, 탄자니 아 등과 같은 현지 사무소에서는 원조공여 기관 간 회의(예시: 베트남 $6 \mathrm{Banks}$ 협의체)와 수원국 원조총괄 기관 주재 협의체에도 활발히 참석하고 있다.

앞으로 $\mathrm{EDCF}$ 는 수원국 정부나 타 공여 기관과의 정책 대화를 계속 발전시켜 현지 개발 환경에 더욱 부합하는 지원 전략을 수립·실행해야 할 것이다. 구체적으로, 프로그램 미션 등 사업 발굴 단계에서 보다 광범위한 수원국 관계자들을 대상으로 다양한 개발 수요를 파악하고, 베트남 사무소의 공여 기관 협의체 활동이 타 지역 사무소로 확산될 수 있도록 현지 공여 기관 협력 전담 인력을 확충해 주는 등의 조치도 고려해 볼 만하다.

\section{다. (권고 사항 5) 수원국 정부의 신청 절차 강화 및 지속적 투자 유도}

$\mathrm{EDCF}$ 는 개발도상국 정부에게 차관을 제공하므로, 차관 신청은 수원국의 관련 법령에 따라 진행된다. 대부분 수원국의 공공투자위원회나 원조총괄 부처에서 사업의 우선순위를 정하고, 국회나 유관 부처의 승인 등을 거쳐 차관 신청이 이루어진다. 한편, $\mathrm{EDCF}$ 는 사업 계획 수립, 사업타당성조사, 사업 심사 등 사업 진행 단계마다 수원국 사업 실시 기관이 사업 완공 이후의 유지·보수 계획을 사전에 수립하고 또 지속적으로 갱신하도록 요구하고 있다.

$\mathrm{EDCF}$ 는 앞으로 개별 프로젝트가 보다 다양하고 포용적인 방식으로 신청되도록 프로그램 미션이나 정부 간 정책 협의 시 수원국의 보다 많은 관계 기관이 참여토록 독려할 필요가 있다. 한편, 사업 종료 이후에도 사업의 지속 가능성을 높이기 위해 수원국 정부의 유지·관리 목적의 투자가 계속되도록 수원국 정부의 운영·관리 계획을 확인하고, 이행 상황을 지속적으로 모니터링해야 한다. 


\section{라. (권고 사항 7) 타 공여 기관과의 협업을 통한 취약국 지원 강화}

$\mathrm{EDCF}$ 는 2017년 5월부터 취약국 지원 가이드라인을 수립하여 최빈국이나 저소득국의 취약성 이슈에 대응하고 있고, 아시아개발은행(Asia Development Bank, ADB), 세계은행(World Bank) 등 $\mathrm{MDB}$ 와의 협조융자를 추진하여 취약국 지원 사업의 개발 효과를 더욱 높이기 위해 노력하고 있다.

$\mathrm{EDCF}$ 는 앞으로 취약국 지원을 더욱 강화하기 위하여 다자개발은행들과 협조융자를 지속적 으로 확대해 나가는 한편, 취약국 거버넌스 개선을 위해 힘쓰고 있는 OECD DAC 거버넌스네트 워크(Network on Governance, GOVNET)4) 등 국제원조사회 논의에 적극 참여하고, 아프리 카 취약국 지원 경험이 풍부한 미국 국제개발처(United States Agency for International Development, 이하 USAID) 등 해외 양자원조 기관들과도 긴밀히 협력해 나갈 필요가 있다.

\section{3. 시스템 개선 및 소통 강화}

\section{가. (권고 사항 8) ODA 사업 승인 절차 간소화 및 현장 권한 강화}

$\mathrm{EDCF}$ 는 국제적으로 통용되는 차관 사업 승인 절차와 유사한 일련의 절차5)를 운영하면서도 승인 절차 촉진을 위해 사업 발굴 단계에서부터 사업 관리에 만전을 기하고 있다. 한편, $\mathrm{EDCF}$ 는 수원국 현지 사무소에 적절한 책임과 권한을 부여하여 본부 지원, 연락 등의 제한적 역할에 그치지 않고 현지 네트워크를 십분 활용하여 사업 전 단계에 적극 참여케 하고 있다.

$\mathrm{EDCF}$ 는 앞으로 사업 승인 절차가 더욱 원활히 진행될 수 있도록 사업개념서(Project Concept Paper, PCP) 수립, 사업타당성조사(feasibility study) 등의 사업 준비 단계 절차를 더욱 신속히 추진하면서 수원국 내 차관 신청 절차 또한 빠르게 진행되도록 밀착 모니터링해야 한다. 한편, 현장 권한을 더욱 강화하기 위하여 해외 사무소 조직 및 인원을 지속 확대하고, 해외 사무소가 사업 주요 단계에서 좀 더 실질적인 역할을 할 수 있도록 더 많은 권한과 책임을 부여하는 방안을 강구해야 할 것이다.

4) $\mathrm{OECD} \mathrm{DAC}$ 거버넌스네트워크(GOVNET)는 수원국의 효과적·포용적 거버넌스 구축, 공공 부문 역량 강화, 부패 방지 등을 위한 DAC 산하기구를 말함.

5) $\mathrm{EDCF}$ 차관사업 승인 절차는 다음과 같다. 차관 신청 $\rightarrow$ 사업 심사 $\rightarrow$ 정부 지원방침 결정(차관 승인) 


\section{나. (권고 사항 9) 통합적 ODA 추진을 통한 개발 효과성 제고 및 의사소통 증진}

$\mathrm{EDCF}$ 는 수원국 원조 총괄 기관과의 현지 소통 채널을 구축하고 지원 사업 발굴 및 시행을 위해 긴밀히 협의하고 있으며, 재외 공관 주관의 $\mathrm{ODA}$ 현지 협의체에도 참석하여 한국의 유관 기관과 사업 정보를 공유하고 있다. 또한 한국 정부 내의 $\mathrm{EDCF}$ 관계기관협의회, 국제개발사업 심의회 등은 물론 $\mathrm{EDCF}-\mathrm{KOICA}$ 정례협의 등 유무상 연계 협력을 위한 다양한 소통 채널을 구축·운영하고 있다.

$\mathrm{EDCF}$ 는 앞으로 관계기관협의회의 기능을 지속적으로 개선·강화하여 유관 부처 및 무상원 조 기관과 사업 발굴 준비 단계에서부터 사업 정보를 공유하고 또 정부의 융합예산이나 'Fast-track' 제도를 적극 활용하여 차관 사업에 대한 무상원조 연계 지원 가능성을 더욱 높여

나갈 필요가 있다.

\section{다. (권고 사항 10) 개발협력 관련 역량 · 기능 검토 및 인력 계획 수립}

$\mathrm{EDCF}$ 는 그동안 개발협력 역량과 전문성을 갖출 목적으로 지속적인 사업 수 증가에 대응하 여 인력 충원을 단계적으로 확대해 왔다. 또한 기관 내외 교육, 유관 부서와의 인력 교류 등을 통해 금융, 지역, 개발 이슈의 전문성을 강화해 왔다.

$\mathrm{EDCF}$ 는 향후에도 업무 역량을 더욱 강화하기 위하여 조직 역량 진단 등을 통해 필요한 인력 계획을 수립하는 한편, $\mathrm{EDCF}$ 담당 인력에 대한 $\mathrm{ODA}$ 석·박사 학위과정을 지원하고 또 해외 사무소 현지 직원에 대한 한국 초청 연수 등을 도입·실시하는 방안도 고려해야 할 것이다.

\section{4. 시민사회와의 협력 강화}

\section{가. (권고 사항 12) 시민사회와의 파트너십 강화를 통한 협력 전략 마련}

$\mathrm{EDCF}$ 는 유상원조 시행 기관으로서 시민사회 기구를 통한 협력 사업 시행 경험은 없으나, 국무조정실 등 정부 기관이 개최하는 다양한 시민사회 워크솝 등에 참석하여 유상원조 사업을 소개하고 소통을 늘려 나가는 노력을 하고 있다.

$\mathrm{EDCF}$ 는 앞으로 시민사회와의 파트너십을 더욱 강화하기 위하여 타국 선진 원조 기관의 시민사회 기구 협력 사례 등을 조사하여 시민사회가 유상원조 사업에 참여 또는 협업할 수 있는 방안을 다각도로 모색해야 할 것이다. 


\section{IV. 시사점 및 결론}

한국이 $\mathrm{OECD} \mathrm{DAC}$ 회원국으로서 선진 공여국이 되기 위해서는 동료검토에 나온 권고 사항을 충실히 이행해야 할 것이다. 다만, 권고 사항은 어디까지나 동료 회원국의 권고일 뿐이므 로 감사 지적 사항처럼 너무 부담스럽게 받아들일 필요는 없다고 본다. 더욱이 권고 사항이 한국의 역사나 특수한 상황을 고려하지 않은 측면이 있으므로, 한국의 현실적인 여건도 충분히 감안하면서 권고 사항을 이행하면 될 것이다.

$\mathrm{EDCF}$ 입장에서 보면, 2017년 동료검토도 2012년의 결과와 마찬가지로 한국 정부의 ODA/ $\mathrm{GNI}$ 목표를 달성하기 위한 지원 규모 확대, 최빈국이나 취약국에 대한 집중 지원 등 차관의 양적 확대를 권고하고 있다. 양적 확대 이외의 권고 사항으로는 비구속성 지원 확대, 성과 관리 및 평가 강화, 현지 정책 대화 심화, 현장 권한 강화 등을 들 수 있다. 이 중에서 특히, 비구속성 지원 확대가 시급하면서도 어려운 과제임에는 틀림없다.

우선 양적 확대에 관한 권고를 보면, $\mathrm{EDCF}$ 차관 사업은 대부분 수원국이 직접 발주하는 프로젝트 형식의 사업이다 보니 한국의 무상원조기관이 직접 발주하는 단년도 무상원조 사업과 는 달리, 단기간 내 예산집행 확대가 용이하지 않다. 사업 진행은 수원국의 내부 승인 절차를 엄격히 따라야 하고, 자금 집행은 수년에 걸쳐 공정률에 따라 조금씩 이뤄지기 때문에 사업 진행에 변수가 많은 편이다. 물론 $\mathrm{EDCF}$ 는 사업 진행 상황 모니터링 등 철저한 사업 관리를 통해 지연 요인을 최소화하려고 노력하지만 현실은 그렇게 녹록하지 않다.

자금 집행을 확대하는 게 어렵더라도 $\mathrm{EDCF}$ 가 차관 규모를 대폭 늘리고 차관 사업의 가시성 을 높이기 위해서는 개발도상국의 대규모 랜드마크 사업을 적극 발굴하여 차관 승인 규모를 더욱 확대하고, 가용한 개발 재원을 최대한 동원해야 할 것이다. 특히, 수출신용기관, 개발금융 기관, 타 원조공여기관, 국제개발금융기구 등과 긴밀히 협력하여 협조융자 규모를 더욱 늘리고, 민관협력 사업인 $\mathrm{PPP}$ 사업에 대한 지원 확대 등을 통해 민간 재원 동원에 필요한 촉매제 역할을 충실히 수행해야 한다.

한편, $\mathrm{EDCF}$ 는 차관 사업의 효과성을 높이기 위해 한국 무상원조기관의 지원도 절실한 형편 이다. 특히, 사업 준비 단계의 사업타당성조사 지원, 사업 진행 중 교육·훈련 지원, 완공 사업의 사후관리 지원 등을 위해서는 무상원조 방식의 기술협력이 필요하기 때문이다. 최근 정부가 시행하고 있는 융합예산 편성, N-2년제 보완을 위한 'Fast track'제도 등은 EDCF 차관 사업에 대한 무상원조 기관의 연계 지원 가능성을 높여 줄 것으로 기대한다. 
이번 동료검토 권고 사항의 하나인 비구속성 차관 지원을 확대하기 위해서는 본문에 언급한 바와 같이 우선적으로 다자개발은행과의 협조융자, 민간 제안 $\mathrm{PPP}$ 사업 지원, 프로그램 차관 제공 등의 비구속성 지원 수단을 최대한 활용해야 할 것이다. 그러나 타 원조 선진국의 사례에 비춰 볼 때, 한국의 차관 지원 규모가 계속 확대되고 또 수원국의 소득 수준 향상으로 현지 자금 사정이 개선되면 일반 차관도 비구속성으로 지원해 달라는 요구가 높아질 것으로 예상된다.

따라서 $\mathrm{EDCF}$ 관계자들은 일반 차관까지 비구속성으로 제공해야 하는 상황에 미리 대비해야 할 것이다. 먼저, 한국 기업들은 해외 사업 수주 경험을 계속 쌓으면서 국제 경쟁입찰을 통해서 라도 차관 사업을 당당히 수주할 수 있는 기술·가격의 경쟁력을 키워 나가야 한다. 한편, 한국 정부의 예산으로 지원하는 $\mathrm{EDCF}$ 사업을 타 경쟁국이 수주하는 것을 이해할 정도의 국민적 공감대는 아직 부족하므로, 한국 정부와 $\mathrm{EDCF}$ 는 차관의 비구속성화에 대한 국민의 부정적 인식을 개선하려고 노력해야 한다. 또한 극히 예외적인 경우에만 비구속성 지원을 허용하는 현행 관련 법령에 대한 종합적인 개편 방향도 강구해야 할 것이다. 


\section{참고 문헌}

한국수출입은행. 2017. "2017 OECD DAC 동료검토의 이해.” vol.6(3). 서울: 한국수출입은행.

관계부처 합동. 보도 자료 " $\mathrm{OECD}$ 가 바라본 대한민국의 $\mathrm{ODA}$ - 우리 $\mathrm{ODA}$ 에 대한 $\mathrm{OECD}$ 개발원조위원회 <동료검토 보고서> 발간.” (배포일: 2018.02.06.)

OECD. 2016. "Taking stock of aid to least developed countries (LDCs)." Paris: Organisation for Economic Cooperation and Development (OECD), available at https://www.oecd.org/dac/financing-sustainable-development/Takingstock-of-aid-to-least-developed-countries.pdf (접속일: 2018.2.14.) 2017. "Review of the Development $\mathrm{Co}^{-}$operation Policies and Progrmames of Korea." DCD/DAC/AR(2017)2/26/PART1/FINAL. Paris: Organisation for Economic Cooperation and Development (OECD). 